\title{
Gene therapy of gastric cancer using LIGHT-secreting human umbilical cord blood-derived mesenchymal stem cells
}

\author{
Xinhong Zhu $\cdot$ Dongming Su $\cdot$ Shiying Xuan \\ Guiliang Ma $\cdot$ Zhenbo Dai $\cdot$ Tongyun Liu · \\ Dongqi Tang $\cdot$ Weizheng Mao $\cdot$ Chenfang Dong
}

Received: 24 January 2012/Accepted: 11 May 2012/Published online: 1 August 2012

(c) The International Gastric Cancer Association and The Japanese Gastric Cancer Association 2012

\begin{abstract}
Background Mesenchymal stem cells (MSCs) have the ability to migrate into tumors and therefore are potential vehicles for the therapy of malignant diseases. In this study, we investigated the use of umbilical cord blood mesenchymal stem cells (UCB-MSCs) as carriers for a constant source of transgenic LIGHT (TNFSF14) to target tumor cells in vivo.
\end{abstract}

\section{Zhu}

Department of Central Laboratory,

Qingdao Municipal Hospital, Qingdao, China

D. Su

Center of Metabolic Disease Research,

Nanjing Medical University, Nanjing, China

S. Xuan

Department of Gastroenterology, Qingdao Municipal Hospital, Qingdao, China

G. Ma · T. Liu · W. Mao $(\square)$

Department of General Surgery, Qingdao Municipal Hospital, 5 Donghai Middle Road, Qingdao 266071, China

e-mail: maoweizheng@hotmail.com

Z. Dai

Endoscopy Department, Tianjin Medical

University Affiliated Cancer Hospital, Tianjin, China

D. Tang

Department of Pathology, Immunology and Laboratory

Medicine, University of Florida College of Medicine,

Gainesville, FL 32610-0275, USA

C. Dong $(\bowtie)$

Department of Molecular and Cellular Biochemistry, Markey Cancer Center, University of Kentucky School of Medicine, BBSRB Room B336, 741 South Limestone, Lexington, KY 40506-0509, USA

e-mail:dcf466@gmail.com
Methods Lentiviral vectors carrying LIGHT genes were constructed, producing viral particles with a titer of $2 \times 10^{8}$ TU/L. Fourteen days after UCB-MSCs transfected by LIGHT gene packaged lentivirus had been injected into mouse gastric cancer models, the expression levels of LIGHT mRNA and protein were detected by reverse transcription polymerase chain reaction (RT-PCR) and enzyme-linked immunosorbent assay (ELISA). Then the tumors' approximate volumes were measured.

Results The treatment with MSC-LIGHT demonstrated a strong suppressive effect on tumor growth compared to treatment with MSC and $\mathrm{NaCl}(p<0.001)$. Examination of pathological sections of the tumor tissues showed that the areas of tumor necrocis in the MSC-LIGHT group were larger than those in the MSC group. Moreover, we found that MSCs with LIGHT were able to significantly induce apoptosis of tumor cells. The expression levels of LIGHT mRNA and protein were significantly higher in the UCBMSCs with the LIGHT gene than the levels in UCB-MSCs $(p<0.001)$.

Conclusion These results suggest that UCB-MSCs carrying the LIGHT gene have the potential to be used as effective delivery vehicles in the treatment of gastric cancers.

Keywords LIGHT (TNFSF14) - Gastric cancer · Lentiviral vector - Umbilical cord blood mesenchymal stem cells (UCB-MSCs)

\section{Introduction}

Gastric cancer is one of the most common malignant diseases. A 2005 analysis of the worldwide incidence of and mortality from cancer showed that 934,000 cases of gastric 
cancer occurred in 2002 and that 700,000 patients die annually of this disease $[1,2]$. Conventional cancer therapies have not had a major impact on the survival of human gastric cancer. Thus, new treatment modalities are urgently required to improve the prognosis of patients with gastric cancer, which may improve survival.

Mesenchymal stem cells (MSCs) are promising cellular vehicles for the therapy of malignant diseases as they have the ability to migrate into tumors and even track infiltrating tumor cells [3-8]. Highly proliferative MSCs derived from bone marrow (BM-MSCs) were the first recognized source of MSCs, but injury caused during harvesting impedes large-scale production. Isolating MSCs from bone marrow is easier than isolation from umbilical cord blood (UCB), and no significant difference has been observed between the two sources in morphology or immune phenotype [9]. However, stem cells from cord blood have a longer survival rate and more reproductive activity, making them an attractive alternative to BM-MSCs.

UCB-MSCs as vehicles to treat tumors have been investigated in some studies. Kim et al. [10] found that human UCB-MSCs displayed tropism for human glioma and that treatment with stTRAIL-secreting UCB-MSCs had significant antitumor effects compared with adenoviral TRAIL gene therapy. Bhoopathi et al. [11] evaluated the role of matrix metalloproteinase (MMP)-2 in the tropism of UCB-MSCs in a human medulloblastoma tumor model. In other studies, CXCR1- or CXCR4-transfected UCB-MSCs showed superior capacity to migrate toward glioma cells in a Transwell chamber or to migrate toward gliomas compared to primary human (h) UCB-MSCs $[12,13]$.

LIGHT is a member of the tumor necrosis factor (TNF) receptor superfamily [14]. LIGHT is expressed in peripheral blood mononuclear cells, including $\mathrm{T}$ and $\mathrm{B}$ cells, natural killer cells, monocytes, and granulocytes $[15,16]$. This molecule has been shown to play an important role in regulating antitumor immunity by costimulating the proliferation of $\mathrm{T}$ cells and triggering apoptosis of various tumor cells [17-21].

In the present study, we successfully engineered UCBMSCs to deliver a secretable form of LIGHT, and we identified that LIGHT-secreting UCB-MSCs had remarkable antitumor effects.

\section{Materials and methods}

Plasmid construct

PCD DNA4-HisMax-C-LIGHT plasmids were obtained from the Oncology Laboratory, Affiliated Hospital of Medical College, Qingdao University. LIGHT forward primer (5'-CAGGATCCCCGGGTACCGGTCGCCACCA
TGGAGGAGAGTGTCGTACGGC-3') and reverse primer (5'-TCACCATGGTGGCGACCGGTACCACCATGAAAGC $\left.C C C G A A G-3^{\prime}\right)$ were used for polymerase chain reaction (PCR) to obtain LIGHT genes from pCD DNA4-HisMaxC-LIGHT. The procedure was: pre-denaturation at $94{ }^{\circ} \mathrm{C}$ for $3 \mathrm{~min}$; 30 cycles with denaturation at $94{ }^{\circ} \mathrm{C}$ for $30 \mathrm{~s}$, annealing at $60{ }^{\circ} \mathrm{C}$ for $30 \mathrm{~s}$, and elongation at $72{ }^{\circ} \mathrm{C}$ for $2 \mathrm{~min}$, and final full elongation at $72{ }^{\circ} \mathrm{C}$ for $10 \mathrm{~min}$. The PCR product was purified with a DNA Gel Extraction Kit (Takara, Tokyo, Japan). The purified PCR products of LIGHT genes were ligated with linearized pGC-FU-GFP Vector (Jikai Gene Technology, Shanghai, China), using an In-Fusion cloning kit (BD, Rutherford, NJ, USA), at $23{ }^{\circ} \mathrm{C}$ for $15 \mathrm{~min}$ and then at $42{ }^{\circ} \mathrm{C}$ for $15 \mathrm{~min}$. Then the recombinant clones were transformed into Escherichia coli DH5 $\alpha$ by the $\mathrm{CaCl}_{2}$ method, and plasmids were extracted with a mini-plasmid extract kit (Takara), in accordance with the manufacturer's protocol. The clone was confirmed by DNA sequencing (sequencing forward primer: $5^{\prime}-C A A G$ $A G C G A A G G T C T C A C-3^{\prime}$, reverse primer: $5^{\prime}-C G T C G C C G$ TCCAGCTCGACCAG-3').

\section{Lentivirus packaging}

293T cells were obtained from the Stem Cell Research Center, Affiliated Hospital of Medical College, Qingdao University, and maintained the cells with high-glucose Dulbecco's modified Eagle medium (DMEM; GIBCO, Gaithersberg, MD, USA) containing $10 \%$ fetal bovine serum (FBS; GIBCO). The 293T cells at $90 \%$ confluence were used for lentivirus packaging. The plasmid of pGCFU-GFP-LIGHT, the construction plasmid Helper1.0, and the envelope plasmid Helper2.0 (Jikai Gene Technology) were co-transfected into $293 \mathrm{~T}$ cells using lipofectamine 2000 (Invitrogen, Grand Island, NY, USA). After 72 h, the culture medium containing LIGHT gene packaged lentivirus was collected, filtered, and stored at $-80{ }^{\circ} \mathrm{C}$ for further processing. The titer of the lentivirus packaging was detected by real-time fluorescence quantitation PCR. The assessment of green fluorescent protein (GFP) expression normalized by actin in the $293 \mathrm{~T}$ cells was used to measure the titer of packaged lentivirus, using GFP primers (forward: $5^{\prime}$-TGCTTCAGCCGCTACCC-3' ${ }^{\prime}$, reverse: $5^{\prime}$-AGTTC $A C C T T G A T G C C G T T C-3^{\prime}$ ) and actin primers (forward: 5'-GTGGACATCCGCAAAGAC-3', reverse: 5'-AAAGGGT GTAACGCAACTA-3').

Infection of UCB-MSCs by obtained lentiviral particles

Mesenchymal stem cells from human umbilical cord blood (UCB-MSCs) (Peprotech, Rochy Hill, NJ, USA) were maintained with RMPI 1640 (GIBCO) containing $10 \%$ FBS. UCB-MSCs were infected with LIGHT packaged lentivirus 
or GFP empty packaged lentivirus in normal culture medium containing $5 \mu \mathrm{g} / \mathrm{mg}$ polybrene (Millipore, Billerica, MA, USA). After $72 \mathrm{~h}$, the expression of GFP was observed by fluorescence microscopy to choose the best multiplicity of infection (MOI) value. UCB-MSCs and UCB-MSCs-LIGHT were collected and washed twice with $0.9 \% \mathrm{NaCl}$ solution, and then suspended with $0.9 \% \mathrm{NaCl}$ solution.

\section{Establishment of the tumor model}

Male athymic nude mice, purchased from the Animal Production Area of the Chinese Academy of Sciences, Beijing, China were manipulated in accordance with institutional guidelines under approved protocols. The cultivated positive human gastric cancer cells, SGC-7901 $\left(1 \times 10^{8} / \mathrm{ml}\right)$, obtained from the Oncology Laboratory, Affiliated Hospital of Medical College, Qingdao University, were injected subcutaneously into the groins of 15 nude mice. After the models of human gastric cancer in nude mice had been established for 14 days, the 15 nude mice with tumorigenesis were separated into three groups. One group was treated with UCB-MSCs $\left(1 \times 10^{7} / \mathrm{ml}\right)$ containing the LIGHT gene (UCB-MSC-LIGHT), the second group was treated with UCB-MSCs $\left(1 \times 10^{7} / \mathrm{ml}\right)$ containing GFP (UCB-MSC-GFP), and the third group was treated with $0.9 \% \mathrm{NaCl}$; the three groups of mice were injected with these agents subcutaneously around the tumors, at $0.2 \mathrm{ml} /$ per mouse. The latter two groups were both used as negative controls. After receiving UCB-MSC treatment for 14 days, the mice were sacrificed and the tumor tissues were collected for further experiments.

Tumor volume, necrosis areas, and apoptosis detection

The volumes and weights of transplanted gastric tumor tissues were measured determine differences in the appearance of the tumors among the three different treatment groups. The length and width of the tumors were measured in order to obtain the tumor volume: volume $=\left(\right.$ length $\times$ width $\left.^{2}\right) / 2$. The tumor tissues then were embedded in OCT compound and cut into $10-\mu \mathrm{m}$-thick pathological sections. The necrosis areas in the tumor tissues were observed by hematoxylin and eosin (HE) staining in randomly selected high-power fields and scored according to the ratio of the necrosis area to the entire tumor area : no necrosis, 0 ; tumor necrosis area less than a quarter, 1; between a quarter and two quarters, 2; more that two quarters, 3. Apoptosis of the tumor tissues was detected with the Hoechst Apoptosis staining kit (Beyotime, Beijing, China) according to the manufacturer's protocol. Rabbit-anti-human polyclonal caspase-3 antibody (Sigma, St. Louis, MO, USA) was used for an immunohistochemistry assay, which was performed following the manufacturer's instructions. Positive staining for caspase-3 protein presents as brown in the cytoplasm, and is shown partly in the nucleus. A semi-quantitative counting method was used to evaluate positive staining. Ten visual fields under a high-power lens $(\times 400)$ were selected randomly, and the numbers of positive cells in 100 cells per field were counted and calculated.

Expression level of LIGHT observed by reverse transcription (RT)-PCR, enzyme-linked immunosorbent assay (ELISA), and western blotting

The mRNA expression level of the LIGHT gene was analyzed by RT-PCR, using primers (forward primer: 5'-CAAGAGCGAAGGTCTCAC-3', reverse primer: 5'-CTG $A G G C C C C T C A G G A A G G C C-3^{\prime}$ ), normalized by the glyceraldehyde 3-phosphate dehydrogenase (GAPDH) mRNA expression level. The protein expression levels of LIGHT in the UCB-MSC cells and tissues were measured with an ELISA test kit (Peprotech) according to the manufacturer's instructions. Also, western blotting was used to further identify the expression level of LIGHT in UCB-MSC cells. The cells were lysed with RIPA buffer to prepare the protein samples for western blotting. The protein samples were loaded onto a $12 \%$ sodium dodecylsulfate polyacrylamide gel electrophoresis (SDS-PAGE) gel, and then transferred to a polyvinylidene difluoride (PVDF) membrane. After being blocked with $1 \%$ bovine serum albumin (BSA) solution for $1 \mathrm{~h}$, the membrane was incubated with mouse anti-GFP monoclonal antibody (1:100; Santa Cruz Biotechnology, Santa Cruz, CA, USA) overnight at $4^{\circ}$, and then goat anti-mouse secondary antibodies (1:1000; Santa Cruz Biotechnology) were applied to the membrane. Protein expression was detected by an enhanced chemiluminescence (ECL) procedure, according to the manufacturer's instructions (Pierce Biotechnology, Rockford, IL, USA).

Statistical analysis

Student's $t$-tests were used to analyze the data. Data are presented as means $\pm \mathrm{SD} ; p$ values less than 0.05 were considered statistically significant.

\section{Results}

Expression level of LIGHT in UCB-MSCs

We successfully amplified the LIGHT gene (Fig. 1a), ligated the PCR product into the pGC-FU-GFP vector (Fig. 1b), and co-transfected the constructed LIGHT plasmid with packaging plasmids pHelper1.0 and pHelper2.0 into the $293 \mathrm{~T}$ cells. After $12 \mathrm{~h}$, green signals in the $293 \mathrm{~T}$ 
Fig. 1 LIGHT plasmid construction and lentivirus packaging. a Full-length human LIGHT gene amplified from recombinant PCD DNA4HisMax-C-LIGHT plasmid by polymerase chain reaction (PCR). b The recombinant pGC-FU-GFP-LIGHT plasmid identified by PCR at $550 \mathrm{bp}$. c genetically modified (GM) 293T cells were observed by light microscopy $(\times 200)$ after transfection for $12 \mathrm{~h}$. d GM 293 T cells observed by fluorescence microscopy $(\times 200)$. e Virus titer of the lentiviral vector particles was detected by real-time

fluorescence quantitation PCR. $\mathbf{f}$ and $\mathbf{g}$ Melting curve of green fluorescent protein (GFP) and actin as controls showing unimodality staining, showing no pollution, no primer dimmers and non-specificity amplification a

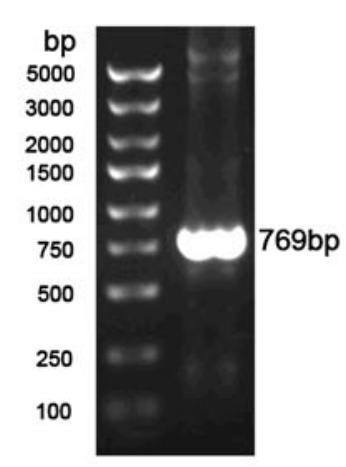

C

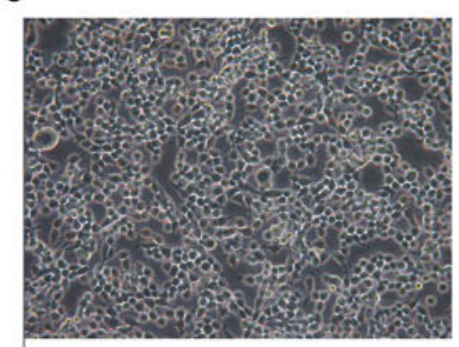

$200 \times$

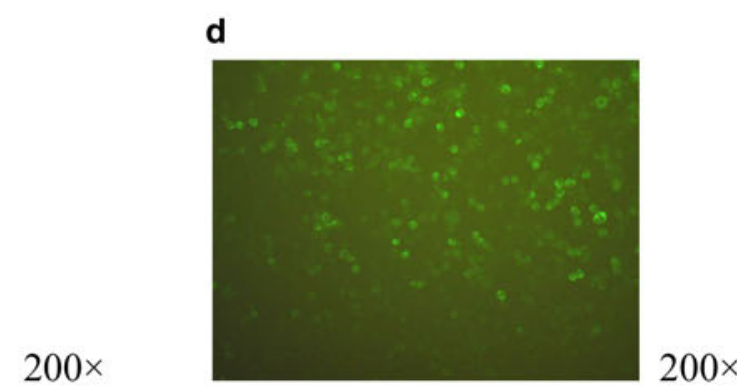

$200 \times$

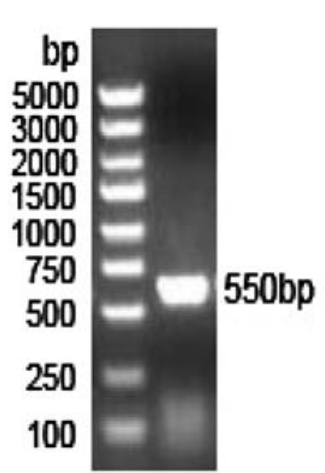

e
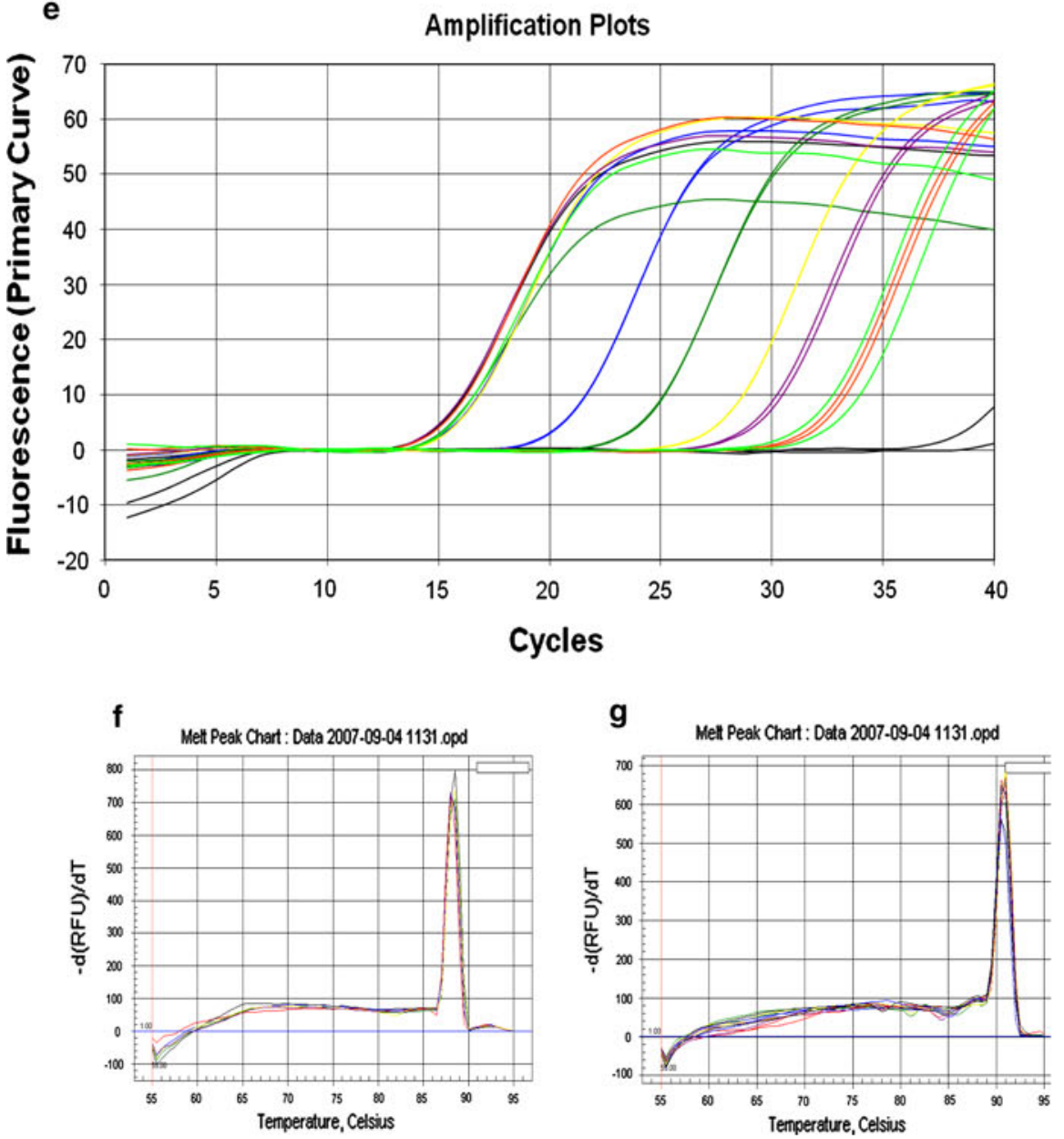
cells were observed by fluorescence microscopy (Fig. 1c, d). It was suggested that the LIGHT gene was successfully transfected into the $293 \mathrm{~T}$ cells. The titer of the LIGHTpackaged lentivirus was examined by real-time quantitative
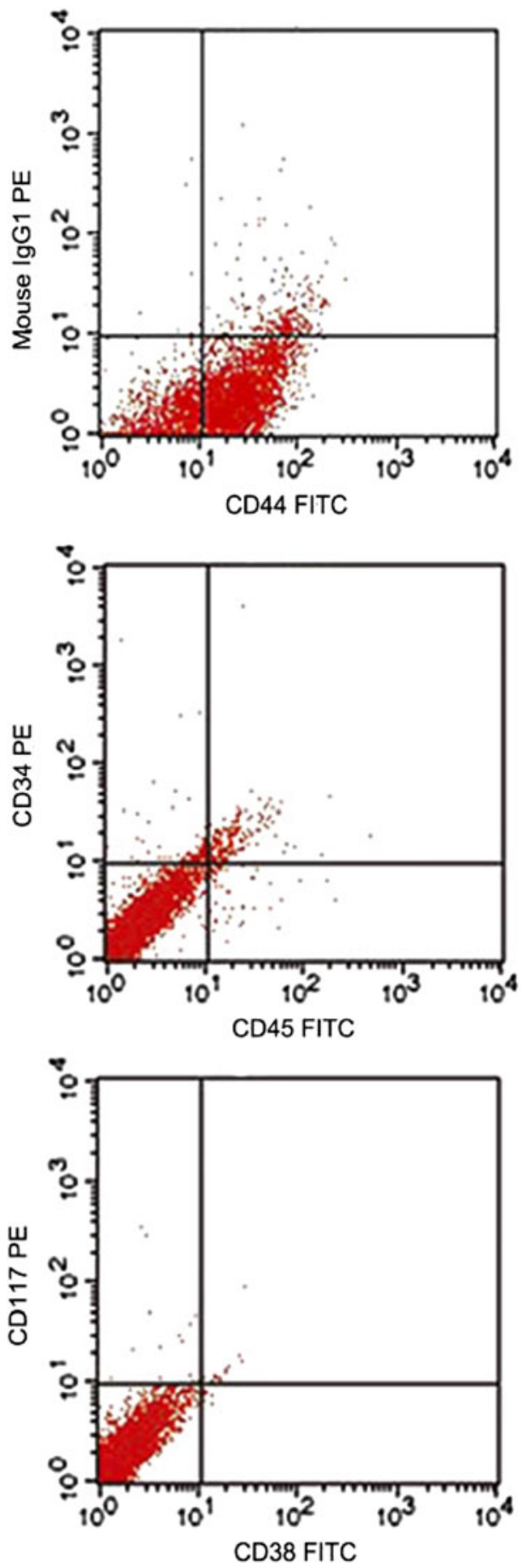

Fig. 2 The expression of surface antigens on GM umbilical cord blood mesenchymal stem cells (UCB-MSCs) detected by flow cytometry. GM UCB-MSCs were immunolabeled with a specific monoclonal antibody for the indicated surface antigen, and showed high expression levels of CD44 (65.23 \%), CD105 (94.71 \%), CD29
PCR with actin as a reference gene. The results showed that the titer of the lentivirus containing the LIGHT gene was $2 \times 10^{8} \mathrm{TU} / \mathrm{L}$, which is enough for UCB-MSC infection (Fig. 1e-g).
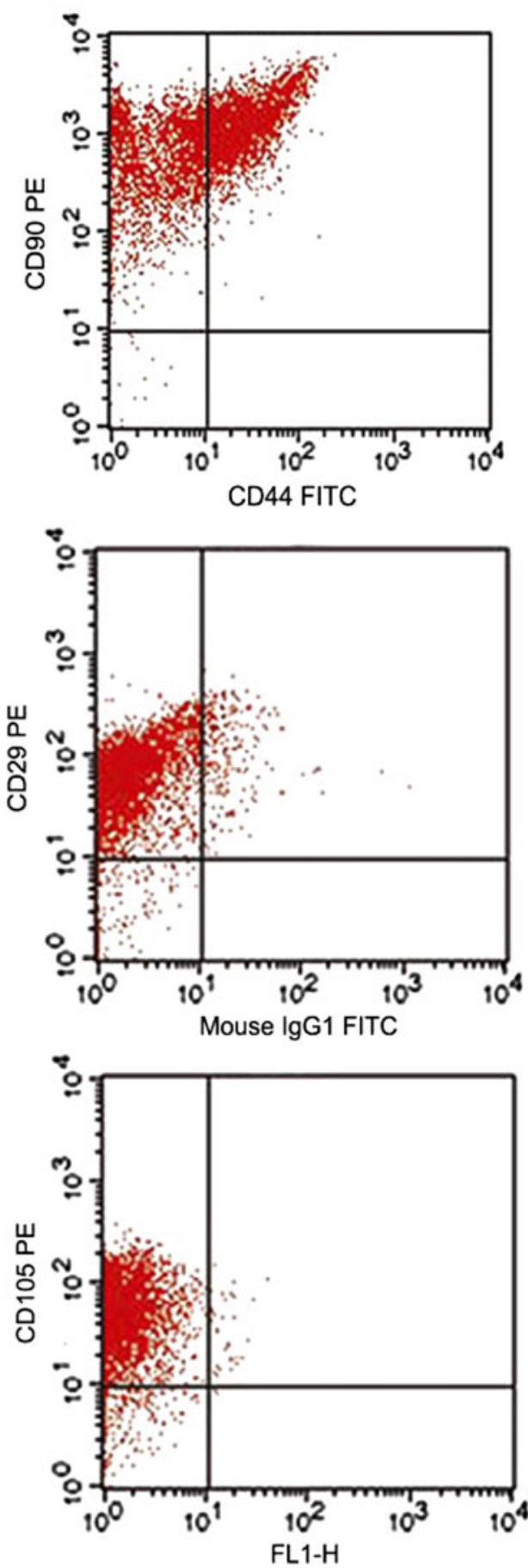

$(95.43 \%)$, and $\mathrm{CD} 90(99.10 \%)\left(\mathrm{CD} 44^{+} \mathrm{CD} 105^{+} \mathrm{CD} 29^{+} \mathrm{CD} 90^{+}\right)$, and no expression of $\mathrm{CD} 38(0.30 \%), \mathrm{CD} 117$ (0.17\%), CD45 $(1.25 \%)$, and $\mathrm{CD} 34(0.51 \%)\left(\mathrm{CD} 38^{-} \mathrm{CD} 117^{-} \mathrm{CD} 45^{-} \mathrm{CD} 34^{-}\right) . P E$ phycoerythrin, FITC fluorescein isothiocyanate, FL1-H FL1 detection channel-H 
The UCB-MSCs were infected by the LIGHT-packaged lentivirus or pGF-FU-GFP empty vector packaged lentivirus, with the untreated UCB-MSCs serving as a negative control. Similar to the phenotypic characterization of UCBMSCs described in previous studies [22], we found that the UCB-MSCs had high expression levels of CD44, CD105, CD29, and CD90, and no expression of CD38, CD117, CD45, and CD34 (Fig. 2). The MOI was 10 when the infection rate reached $80 \%$. The expression of LIGHT in the UCB-MSCs was checked by fluorescence microscopy. The green signals were detected both in the LIGHTpackaged lentivirus-treated group (Fig. 3a) and in the empty vector packaged lentivirus-treated group (Fig. 3b), with no green signals in the negative control group of untreated UCB-MSCs (Fig. 3c), which grew well, as shown under a light microscope (Fig. 3d). UCB-MSCs were transfected with the LIGHT gene in the second passage. After 5-6 passages, UCB-MSCs would have the capacity of differentiation. Every passage is about 4-5 days. GFP could be observed 20-30 days after transfection.

The expression level of LIGHT was further checked by ELISA and western blotting. The results of the ELISA showed that the LIGHT protein concentration in the UCBMSC-LIGHT group $(1.79 \pm 0.34 \mathrm{ng} / \mathrm{ml})$ was obviously higher than that in the UCB-MSC-GFP group $(0.74 \pm$ $0.21 \mathrm{ng} / \mathrm{ml})$ or the UCB-MSC group $(0.75 \pm 0.11 \mathrm{ng} / \mathrm{ml})$, with a significant difference, $p<0.001$ (Fig. 3e). In addition, a GFP-LIGHT band with molecular weight $55 \mathrm{kD}$ was detected by western blotting in the UCB-MSC-LIGHT group, and a GFP band (29 kD) was observed in the UCBMSC-GFP group, while no band existed in the UCB-MSC control group (Fig. 3f). All these data suggested the UCBMSCs were successfully infected by the LIGHT-packaged lentivirus and were able to efficiently express the LIGHT protein.

To evaluate the effect of the transfected LIGHT on the viability of UCB-MSCs, we determined the cell death rate by examining propidine iodide (PI) and Annexin V staining at 24 and $48 \mathrm{~h}$ after transfection. No significant difference was observed among the UCB-MSC, UCB-MSC-GFP, and UCB-MSC-LIGHT groups $(p>0.05)$ (Fig. 4 ).

Antitumor effect of UCB-MSC-LIGHT in gastric cancer models

The gastric cancer models were injected with LIGHT or GFP expressed UCB-MSCs, with $\mathrm{NaCl}$ injection as a negative control. After treatment for 14 days, the volumes and weights of tumor tissues were measured (Table 1).
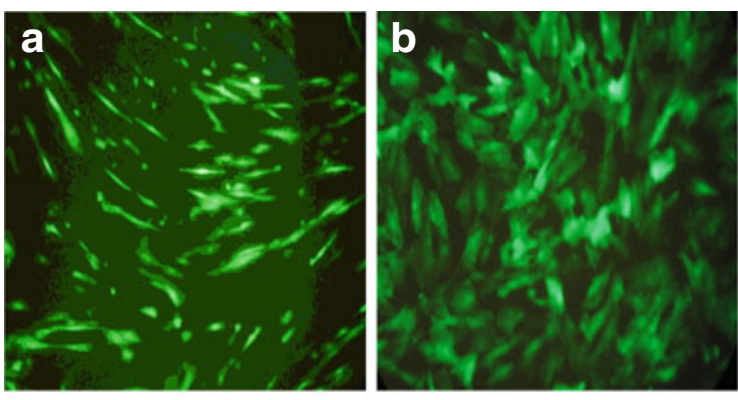

e

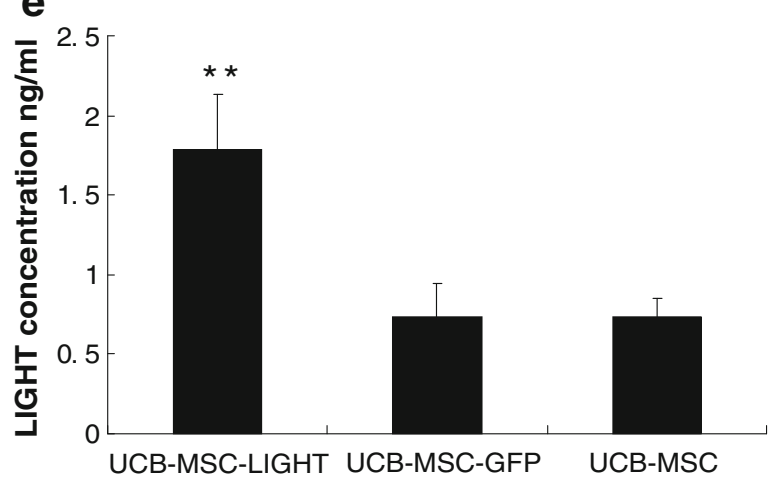

Fig. 3 LIGHT expression in UCB-MSCs in vitro. a LIGHT-GFP expression in UCB-MSCs detected by fluorescence microscopy $(\times 200)$. b GFP expression in UCB-MSC $(\times 200)$. c Untreated UCB-MSC $(\times 200)$. d Untreated UCB-MSC under light microscope $(\times 200)$. e LIGHT protein tested by enzyme-linked immunosorbent
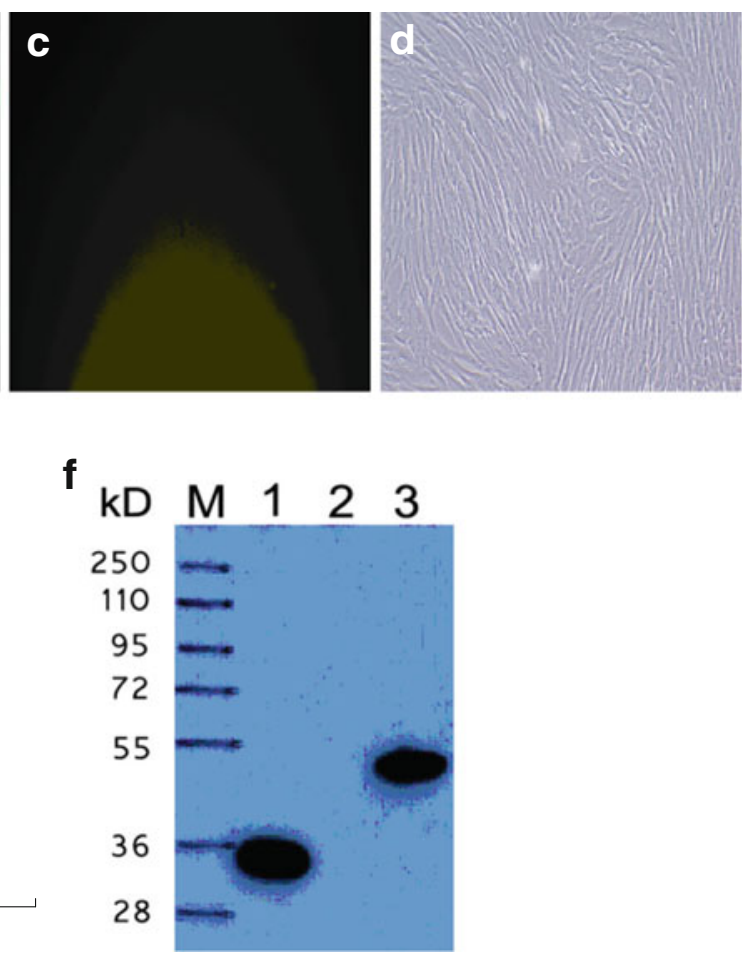

assay (ELISA), ${ }^{* *} p<0.01$. f LIGHT detection by western blotting. Lane $M$ protein marker, lane 1 GFP protein, lane 2 no GFP protein expression in untreated UCB-MSC, lane 3 LIGHT-GFP proteins at $55 \mathrm{kD}$ 
Fig. 4 Flow cytometric analysis for cell viability by $P I$ propidine iodide and Annexin V staining. Upper images flow cytometric analysis of cell viability for UCB-MSCLIGHT, UCB-MSC-GFP, and $\mathrm{UCB}-\mathrm{MSC}$ at $24 \mathrm{~h}$ after transfection. Lower image comparison of cell death rate among the three groups
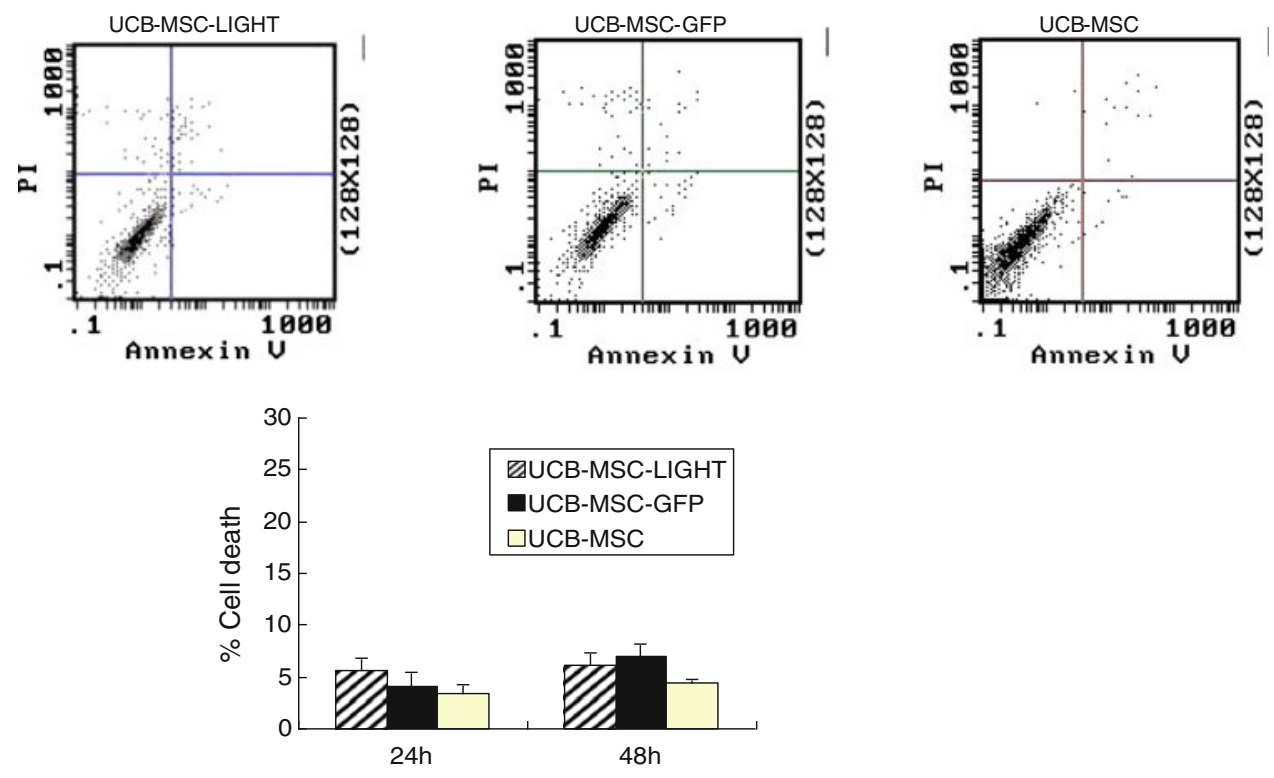

Table 1 Tumor weight, volume and net mouse body weight

\begin{tabular}{llcll}
\hline Group & Net mouse body weight $(\mathrm{g})$ & Tumor weight $(\mathrm{mg})$ & Tumor volume $\left(\mathrm{cm}^{3}\right)$ & Tumor inhibition rate $(\%)$ \\
\hline UCB-MSC-LIGHT & $30.43 \pm 2.08$ & $847.91 \pm 69.60^{* *}$ & $1.27 \pm 0.19^{* *}$ & 48.01 \\
UCB-MSC & $31.25 \pm 2.75$ & $1,017.69 \pm 110.78^{* *}$ & $1.88 \pm 0.21^{*}$ & 37.60 \\
$\mathrm{NaCl}$ & $30.77 \pm 3.01$ & $1,630.91 \pm 102.33$ & $2.27 \pm 0.23$ & \\
\hline
\end{tabular}

Tumor inhibition rate $=(\mathrm{NaCl}$ group tumor weight $-\mathrm{MSC}$ group tumor weight $) / \mathrm{NaCl}$ group tumor weight $\times 100 \%$

$* p<0.05, * * p<0.01$

The results showed that the average volumes of the tumors in the MSC-LIGHT-treated group, MSC-treated group, and $\mathrm{NaCl}$ group were $1.27 \pm 0.19,1.88 \pm 0.21$, and $2.27 \pm 0.23 \mathrm{~cm}^{3}$, respectively (Fig. 5a-d), with significant differences among the three groups $(p<0.001)$. In addition, the tumor suppression rates in these three groups were calculated. The results showed that the tumor inhibition rates in the MSC-LIGHT-treated group and the MSC-treated group, compared with the $\mathrm{NaCl}$ group, were 48.01 and $37.60 \%$, respectively. In order to confirm that the tumor inhibition effect was caused by the increased LIGHT expression in the tumor tissues, we performed RTPCR to measure the mRNA expression levels of LIGHT in the tumor tissues. The results demonstrated that the mRNA levels of LIGHT in the UCB-MSC-LIGHT-treated group $(2.96 \pm 0.27)$ were higher than those in the $\mathrm{NaCl}$ negative control group $(0.73 \pm 0.10)$ and the UCB-MSCtreated group $(0.88 \pm 0.37)$, with a significant difference ( $p<0.001$, Fig. 6a, b). Furthermore, the mRNA level in the UCB-MSC-LIGHT-treated group was significantly higher than that in the UCB-MSC-treated group. We also used an ELISA to test the protein expression level of LIGHT. The results showed that LIGHT expression was obviously increased in the UCB-MSC-LIGHT-treated group $(167.89 \pm 2.31)$ compared with that in the MSC and $\mathrm{NaCl}$ groups $(73.22 \pm 5.74,49.66 \pm 5.25)$, with $p<0.001$ (Fig. 6c). UCB-MSCs labeled with the fluorescent dye superparamagnetic iron oxide-1,1'-dioctadecyl3,3,3',3'-tetramethylindocarbocyanine perchlorate SP-DiI (Biotium, Hayward, CA, USA), were observed distributing in the transplanted tumors (Fig. 7), indicating that UCB-MSCs have a tropism for tumors.

LIGHT is a member of the TNF receptor superfamily and can trigger apoptosis in various tumor cells [23]. Accordingly, we measured the tumor necrosis area, by H\&E staining. The results showed that the tumor necrosis area in the MSC-LIGHT-treated group was obviously larger than that in the MSC-treated group or the $\mathrm{NaCl}$-treated group (Fig. 8a-c). The average ratios of the tumor necrocis areas in the MSC-LIGHT protein group, MSC group, and $\mathrm{NaCl}$ group were $2.5 \pm 0.25,1.25 \pm 0.30$, and $1.3 \pm 0.12$, respectively $(p<0.001$, Fig. 8 d). These data suggested that UCB-MSC-LIGHT can inhibit tumor growth and cause tumor necrocis. Moreover, UCB-MSC-LIGHT caused more apoptosis in the tumor cells than UCB-MSC and $\mathrm{NaCl}$ (Fig. 9). The Hoechst staining was used to 
Fig. 5 Antitumor effect of UCB-MSC-LIGHT.

a-c Transplanted tumors in $\mathrm{NaCl}$-treated group, UCBMSC-GFP-treated group, and UCB-MSC-LIGHT-treated group. d Growth curves of the transplanted tumors in the MSC-LIGHT group, MSC group, and $\mathrm{NaCl}$ group; each experimental point represents data for five mice. ${ }^{* *} p<0.01$. $d$ day

Fig. 6 Expression of LIGHT in tumor tissues. a Lane $M$ marker; lanes 1, 3, 5 LIGHT mRNA in the UCB-MSC-LIGHT group, UCB-MSC group, and $\mathrm{NaCl}$ group (128 bp); lanes 2, 4, 6 glyceraldehyde 3-phosphate dehydrogenase (GAPDH) mRNA in the $\mathrm{NaCl}$ group, UCB-MSC group, and UCBMSC-LIGHT group (111 bp). b The optical density $(O D)$ values of LIGHT mRNA expressed in the UCB-MSCLIGHT group, UCB-MSC group, and $\mathrm{NaCl}$ control group. c Expression levels of LIGHT protein in the tumor tissues of the $\mathrm{NaCl}$ control group, UCBMSC group, and UCB-MSCLIGHT group, tested by ELISA. $* * p<0.01$ a

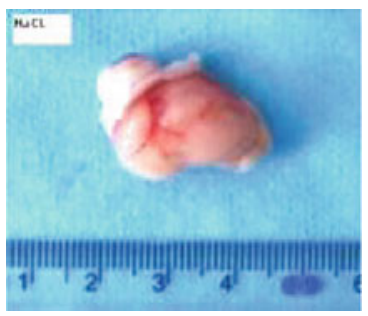

b

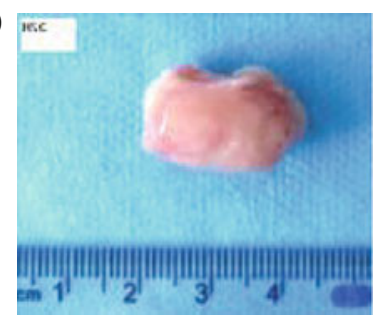

C

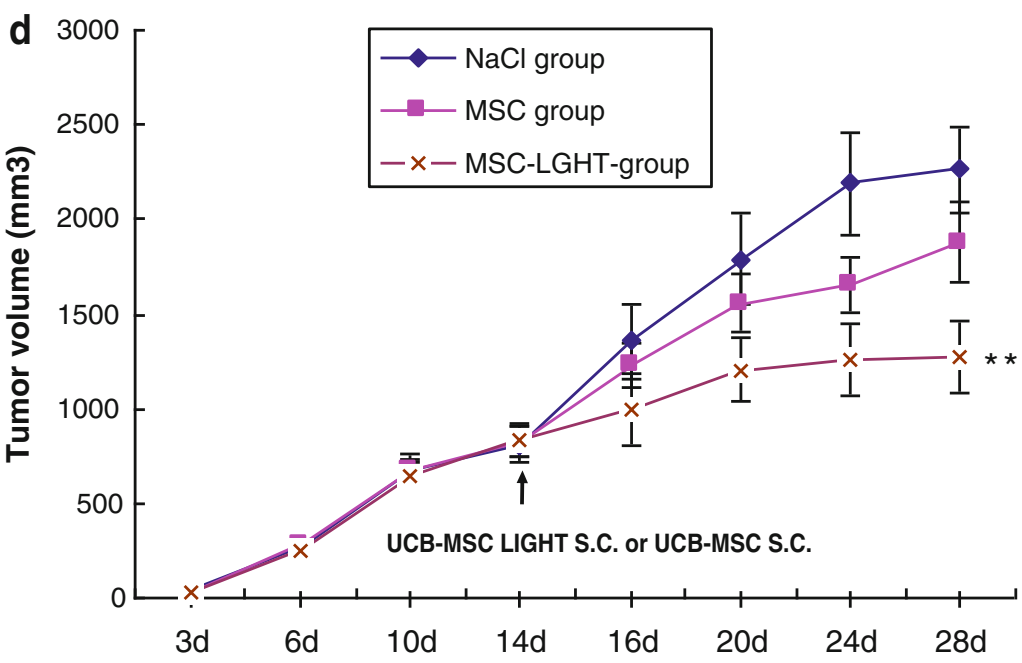

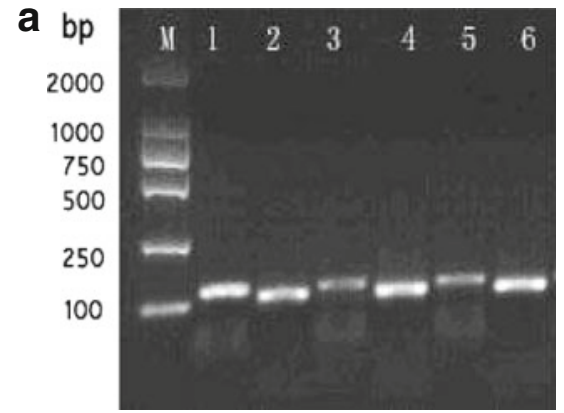

b

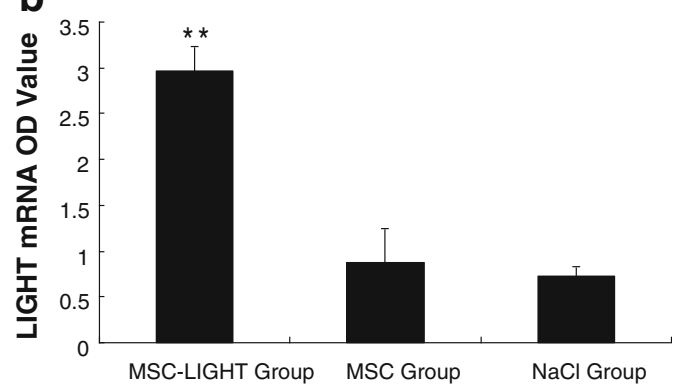

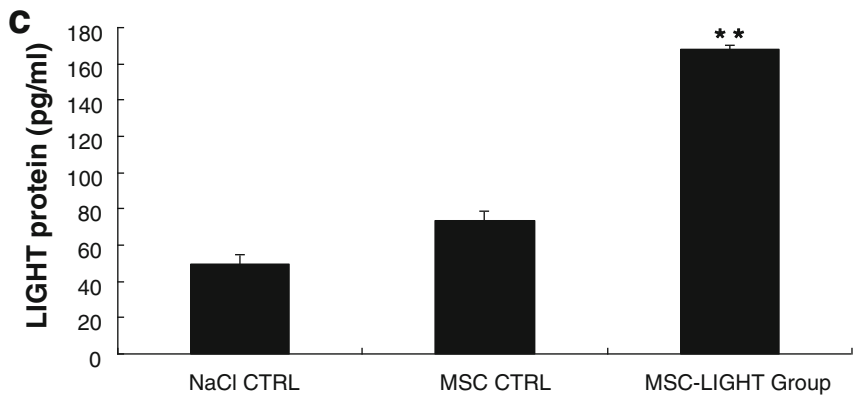

further estimate the effect of LIGHT on apoptosis in the tumor cells. The results showed that the apoptosis caused by UCB-MSC-LIGHT was much greater than that in the UCB-MSC- or NaCl-treated groups (Fig. 9a-c). These results were consistent with the tumor inhibition effect of UCB-MSC-LIGHT, indicating that high expression level of LIGHT in UCB-MSCs can efficiently inhibit tumor growth by inducing more apoptosis in tumor tissues. The expression of caspase-3 protein in tumor tissues was detected by immunohistochemistry (Fig. 10). Positive expression rates of caspase-3 were obviously up-regulated in the UCB-MSC-LIGHT and UCB-MSC groups compared 
Fig. 7 UCB-MSCs labeled with the fluorescent dye, superparamagnetic iron oxide1,1'-dioctadecyl-3,3,3',3'tetramethylindocarbocyanine perchlorate (SP-DiI), were distributed in the transplanted tumors. a Tumor tissues stained with H\&E in the UCB-MSCLIGHT group $(\times 400)$; b fluorescence microscopy in this group $(\times 400)$. c Tumor tissues stained with $H \& E$ in the untreated UCB-MSC group $(\times 400)$; d fluorescence microscopy in this group $(\times 400)$ indicating that UCBMSCs have a tropism for tumors
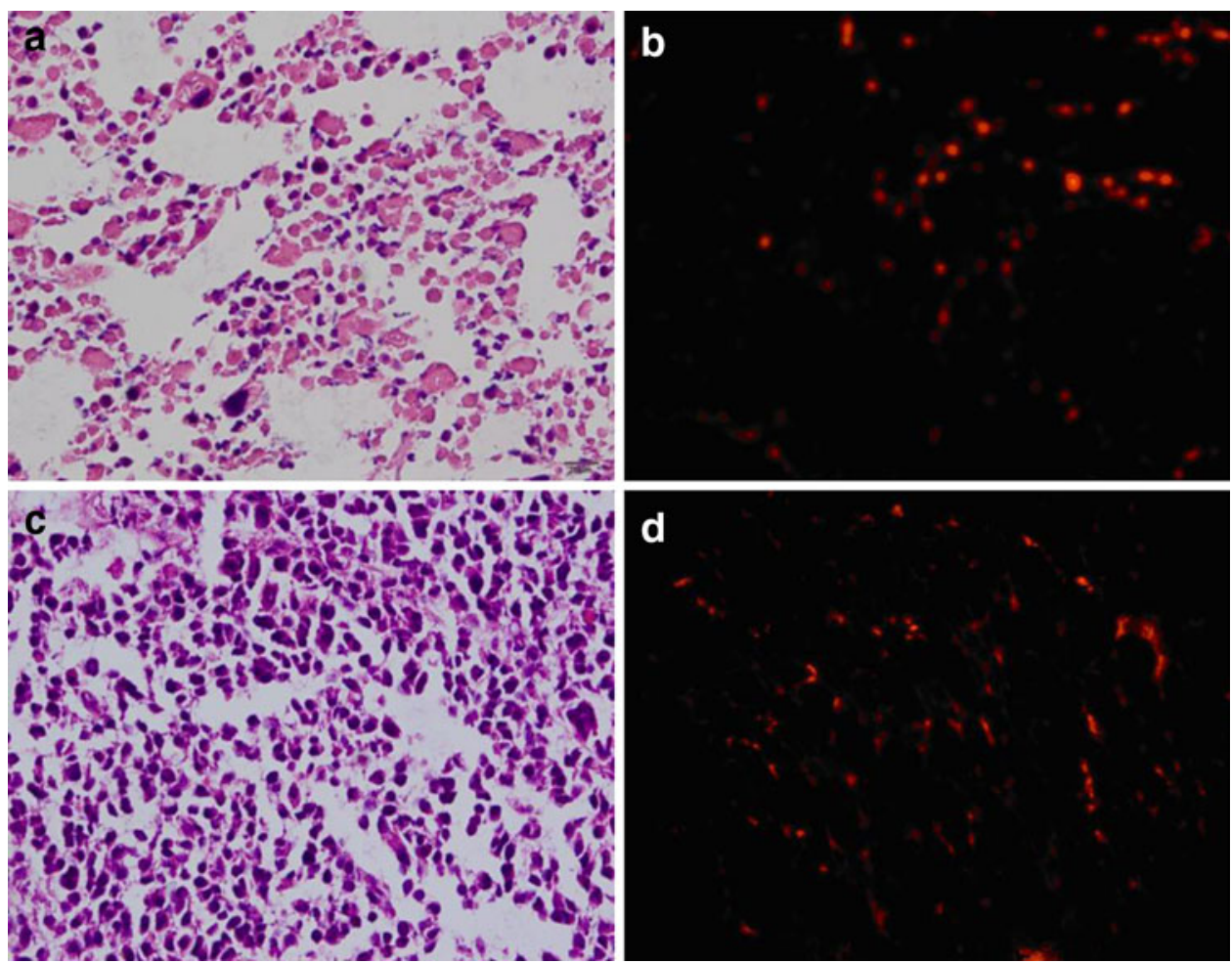
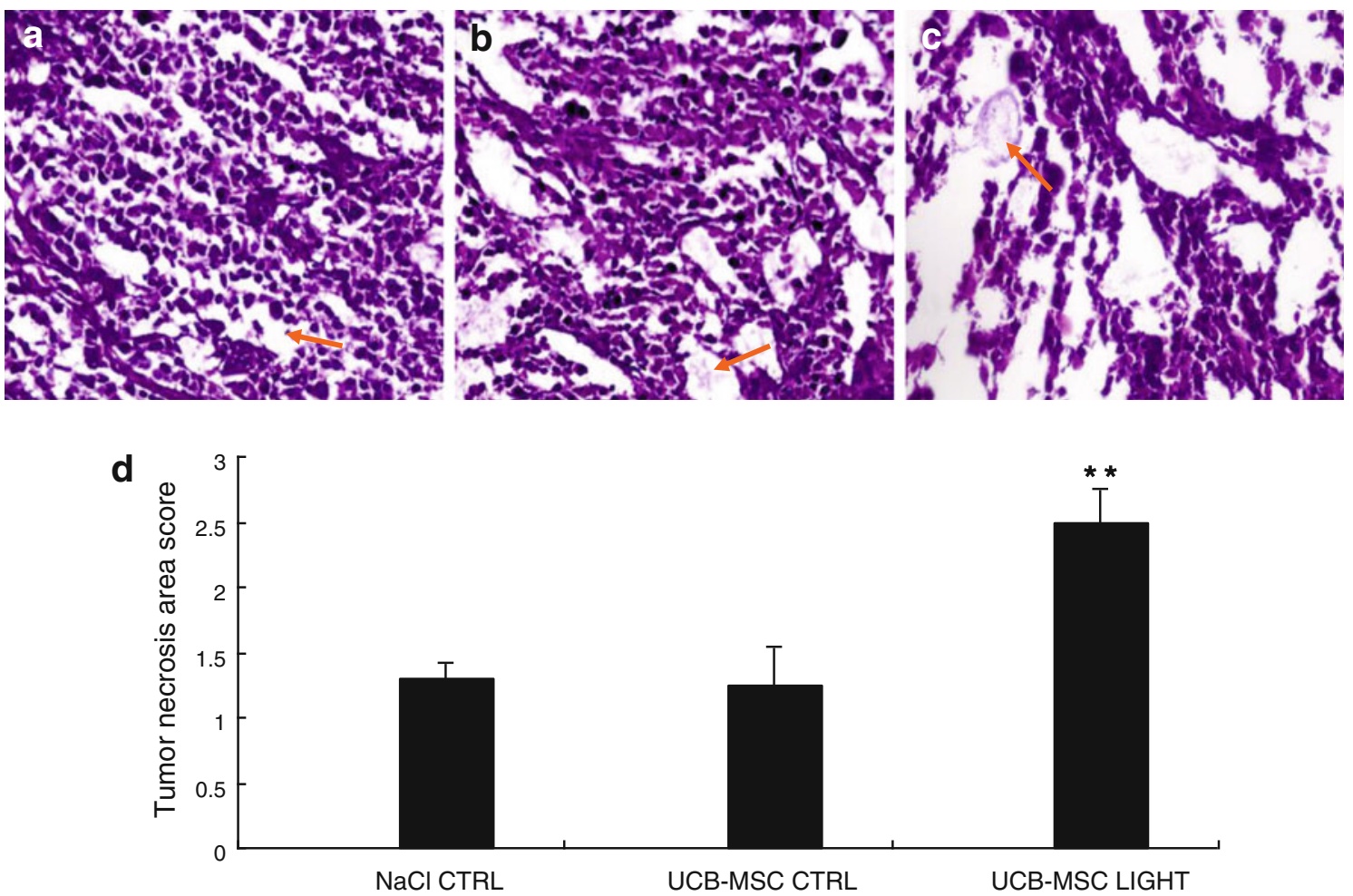

Fig. 8 Necrocis in tumor tissues. H\&E staining of the tumor tissues observed by light microscopy. a $\mathrm{NaCl}$ control group $(\times 100)$; b UCBMSC group $(\times 100)$; c UCB-MSC-LIGHT group $(\times 100)$. The tumor necrocis areas are indicated by arrows. d The tumor necrosis area scores in the UCB-MSC-LIGHT group, UCB-MSC group, and $\mathrm{NaCl}$ group $(* * p<0.001)$. CTRL control 


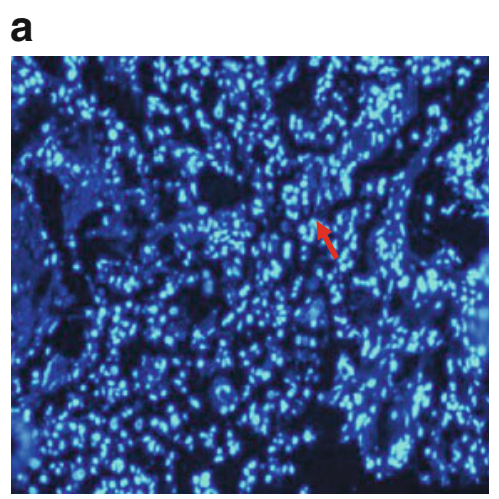

\section{b}

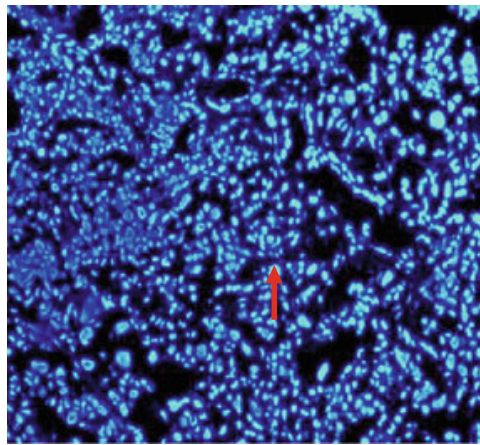

C

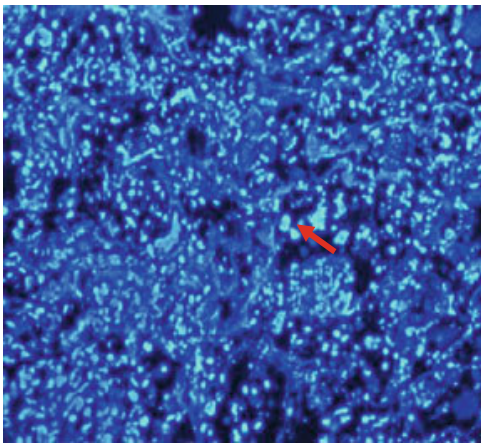

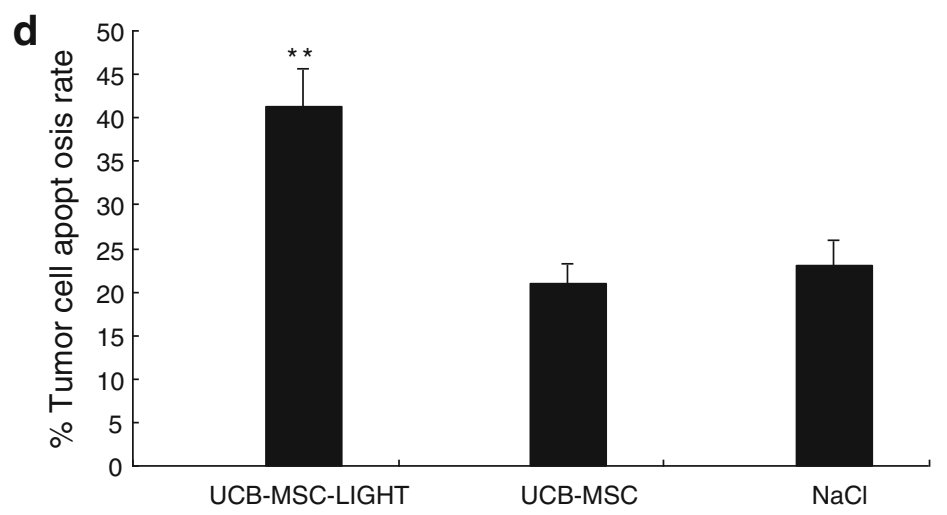

Fig. 9 Apoptosis in tumor tissues. Observation of the apoptosis caused by UCB-MSC-LIGHT (a), UCB-MSC (b) and $\mathrm{NaCl}$ (c) in the tumor tissues, using Hoechst staining $(\times 200)$. The cells indicated by

arrows are apoptotic cells. d UCB-MSC-LIGHT caused more apoptosis in the tumor cells than UCB-MSC and $\mathrm{NaCl}(* * p<0.001)$
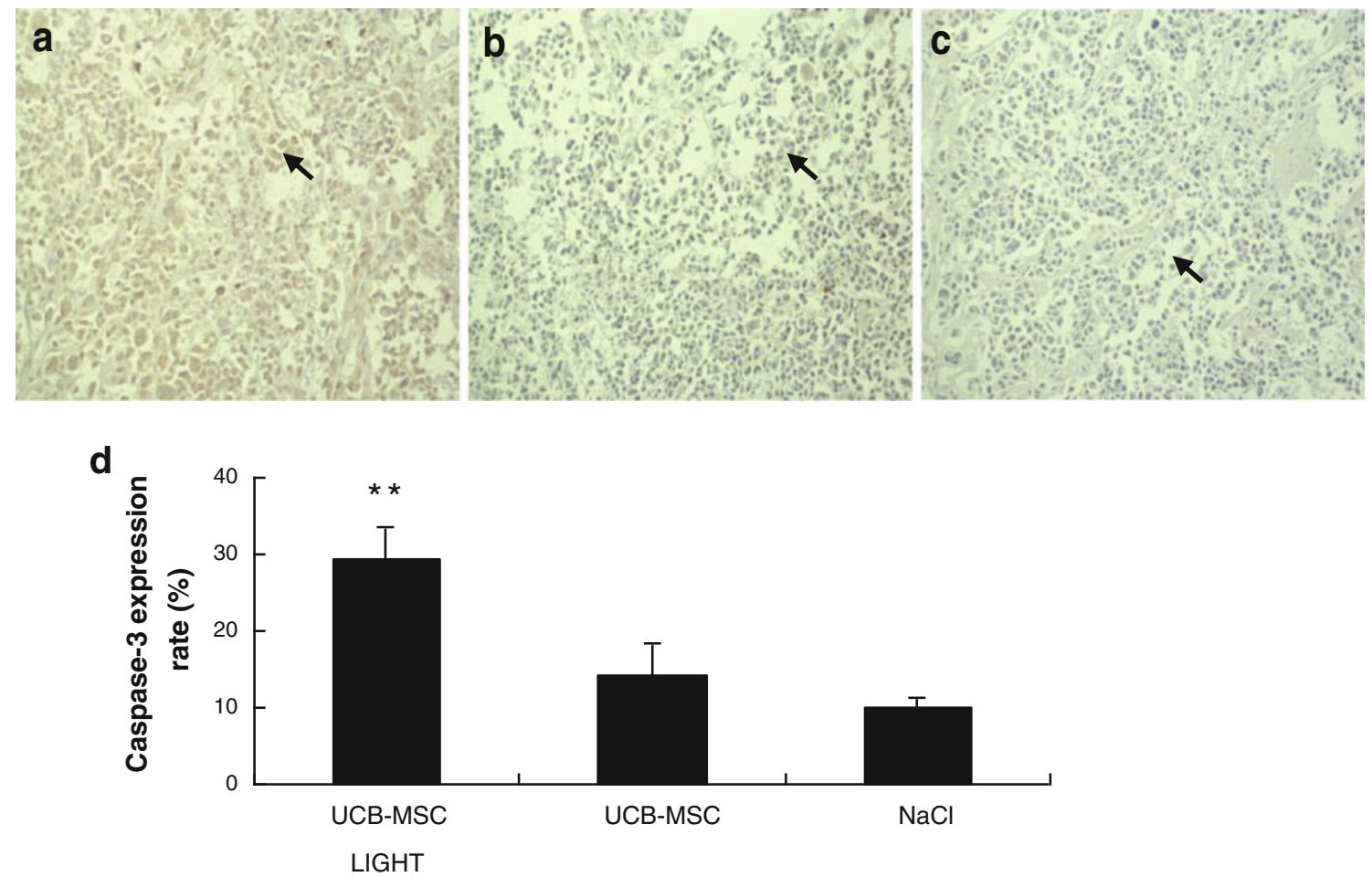

Fig. 10 Caspase-3 expression in tumor tissues. Immunohistochemical assay of caspase-3. a UCB-MSC-LIGHT, b UCB-MSC, $\mathbf{c}$ NaCl $(\times 200)$. The cells indicated by arrows are the caspase-3-positive cells in the tumor tissues. $\mathbf{d}$ Caspase- 3 expression rate 
with that in the $\mathrm{NaCl}$ group, and there was a significant difference between the UCB-MSC-LIGHT and UCB-MSC groups, indicating that UCB-MSC-LIGHT may contribute to cancer apoptosis via caspase-3 activation.

\section{Discussion}

The TNF- $\alpha$ superfamily member LIGHT has potent antitumor activity through direct cytotoxicity and activation of the immune response, and is a promising candidate for cancer therapy [24]. Some studies have demonstrated that LIGHT can treat tumors [25, 26]. Targeting tumor tissues with LIGHT leads to the augmentation of priming and recruitment and the retention of effector cells at tumor sites, a process that directly or indirectly induces strong anti-tumor immunity that inhibits the growth of primary tumors and eradicates metastases [27, 28]. To avoid the toxicity associated with systemic administration and the reduction of anti-cancer effects through a long route, LIGHT should be introduced to certain vectors and concentrated in the local tumor region, serving as a constant source. UCB-MSCs may have the potential to be an efficient source for cell-based gene therapy approaches. In some studies UCB-MSCs have recently been used as cell tools to carry anti-tumor agents [29]. UCB-MSCs are a safe and effective source of cell-transplantation treatment, and these cells can be obtained by a minimally invasive method, without harm to the mother or the infant. Also, UCB-MSCs show no adipogenic differentiation capacity, in contrast to BM-MSCs and adipose tissue (AT)-MSCs [9]. In addition, UCB-MSCs can be easily expanded and transformed by several vectors. With the advantages of UCB-MSCs, it appears that these cells are a feasible vehicle for the delivery of therapeutic agents. In the present study, we efficiently engineered human UCB-MSCs to secrete LIGHT via lentiviral transduction. We identified that UCB-MSCs infected by lentivirus vectors carrying the LIGHT gene had high infection rates, and consistently released LIGHT at high levels. These data indicate that UCB-MSCs delivering a secretable form of LIGHT may be efficient tools for gene therapy.

UCB-MSCs possess tumor-targeting properties and show migratory capacity toward tumor cells $[30,31]$. Our previous investigation showed that the human gastric cancer cells SGC-7901 expressed CXCR4, while UCBMSCs expressed stromal derived factor-1 (SDF-1). The interaction between these two molecules induced the MSCs to migrate into gastric tumor tissues [32]. Nakamizo et al. [7] reported that BM-MSCs have a tropism for brain tumors and thus could be used as delivery vehicles for glioma therapy, and BM-MSCs were seen exclusively within the brain tumors regardless of whether the cells were injected into the ipsilateral or contralateral carotid artery. Using the tracking ability of UCB-MSCs could lead to widespread distribution of therapeutic agents throughout tumors and improve tumor therapy. Based on the advantages of MSCs for use in tumor therapy, we used a xenogenic model of human gastric cancer grown in nude mice to evaluate the therapeutic efficacy of human MSCLIGHT. We found that the average volume of transplanted tumors in the MSC-LIGHT group was obviously smaller than that in the control group, while the tumor necrosis area in the MSC-LIGHT group was larger than that in the control group. In addition, we also found that UCB-MSCLIGHT specifically induced apoptosis through caspase-3 activation. Moreover, as expected, UCB-MSC-LIGHT induced more apoptosis in the tumor cells than UCB-MSC and $\mathrm{NaCl}$. These data indicate that MSC-LIGHT is effective in suppressing tumor growth.

To summarize, we have shown for the first time the use of UCB-MSCs as carriers to deliver LIGHT and we have demonstrated an efficient lentiviral transduction system for MSCs. The engineered UCB-MSCs secreting LIGHT possessed an obvious anti-tumor effect in the xenograft mouse model. Thus, delivering exogenous LIGHT by UCB-MSCs in vivo may represent a prospective method for the treatment of gastric cancers.

Acknowledgments This study was funded by the Open Research Fund Program of the Key Laboratory of Marine Drugs (Ocean University of China) Ministry of Education [No. KLMD (OUC) 200803].

Conflict of interest The authors declare that there is no conflict of interest (no financial and personal relationships with other people or organizations that could inappropriately influence our work).

\section{References}

1. Parkin DM, Bray F, Ferlay J, Pisani P. Global cancer statistics, 2002. CA Cancer J Clin. 2005;55:74-108.

2. Macdonald JS. Gastric cancer-new therapeutic options. N Engl J Med. 2006;355:76-7.

3. Pereboeva L, Komarova S, Mikheeva G, Krasnykh V, Curiel DT. Approaches to utilize mesenchymal progenitor cells as cellular vehicles. Stem Cells. 2003;21:389-404.

4. Aboody KS, Brown A, Rainov NG, Bower KA, Liu S, et al. Neural stem cells display extensive tropism for pathology in adult brain: evidence from intracranial gliomas. Proc Natl Acad Sci USA. 2000;97:12846-51.

5. Studeny M, Marini FC, Champlin RE, Zompetta C, Fidler IJ, et al. Bone marrow-derived mesenchymal stem cells as vehicles for interferon- $\beta$ delivery into tumors. Cancer Res. 2002;62:3603-8.

6. Miletic H, Fischer Y, Litwak S, Giroglou T, Waerzeggers Y, et al. Bystander killing of malignant glioma by bone marrowderived tumor-infiltrating progenitor cells expressing a suicide gene. Mol Ther. 2007;15:1373-81.

7. Nakamizo A, Marini F, Amano T, Khan A, Studeny M, et al. Human bone marrow-derived mesenchymal stem cells in the treatment of gliomas. Cancer Res. 2005;65:3307-18. 
8. Van Damme A, Vanden Driessche T, Collen D, Chuah MK. Bone marrow stromal cells as targets for gene therapy. Curr Gene Ther. 2002;2:195-209.

9. Kern S, Eichler H, Stoeve J, Klüter H, Bieback K. Comparative analysis of mesenchymal stem cells from bone marrow, umbilical cord blood, or adipose tissue. Stem Cells. 2006;24:1294-301.

10. Kim SM, Lim JY, Park SI, Jeong CH, Oh JH, Jeong M, Oh W, Park SH, Sung YC, Jeun SS. Gene therapy using TRAILsecreting human umbilical cord blood-derived mesenchymal stem cells against intracranial glioma. Cancer Res. 2008;23:9614-23.

11. Bhoopathi P, Chetty C, Gogineni VR, Gujrati M, Dinh DH, Rao JS, Lakka SS. MMP-2 mediates mesenchymal stem cell tropism towards medulloblastoma tumors. Gene Ther. 2011;7:692-701.

12. Kim SM, Kim DS, Jeong CH, Kim DH, Kim JH, Jeon HB, Kwon SJ, Jeun SS, Yang YS, Oh W, Chang JW. CXC chemokine receptor 1 enhances the ability of human umbilical cord bloodderived mesenchymal stem cells to migrate toward gliomas. Biochem Biophys Res Commun. 2011;4:741-6.

13. Park SA, Ryu CH, Kim SM, Lim JY, Park SI, Jeong CH, Jun JA, Oh JH, Park SH, Oh W, Jeun SS. CXCR4-transfected human umbilical cord blood-derived mesenchymal stem cells exhibit enhanced migratory capacity toward gliomas. Int J Oncol. 2011;1: 97-103.

14. Mauri DN, Ebner R, Montgomery RI, Kochel KD, Cheung TC, et al. LIGHT, a new member of the LIGHT superfamily, and lymphotoxin are ligands for herpesvirus entry mediator. Immunity. 1998;8:21-30.

15. Zhai Y, Guo R, Hsu TL, Yu GL, Ni J, et al. LIGHT, a novel ligand for lymphotoxin beta receptor and TR2/HVEM induces apoptosis and suppresses in vivo tumor formation via gene transfer. J Clin Invest. 1998;102:1142-51.

16. Tamada K, Shimozaki K, Chapoval AI, Zhai Y, Su J, et al. LIGHT, a LIGHT-like molecule, costimulates T cell proliferation and is required for dendritic cell-mediated allogeneic $\mathrm{T}$ cell response. J Immunol. 2000;164:4105-10.

17. Shi G, Luo H, Wan X, Salcedo TW, Zhang J, et al. Mouse T cells receive costimulatory signals from LIGHT, a TNF family member. Blood. 2002;100:3279-86.

18. Wan X, Zhang J, Luo H, Shi G, Kapnik E, et al. A LIGHT family member LIGHT transduces costimulatory signals into human $\mathrm{T}$ cells. J Immunol. 2002;169:6813-21.

19. Shi G, Mao J, Yu G, Zhang J, Wu J. Tumor vaccine based on cell surface expression of DcR3/TR6. J Immunol. 2005;174:4727-35.

20. Harrop JA, Reddy M, Dede K, Brigham-Burke M, Lyn S, et al. Antibodies to TR2 (herpesvirus entry mediator), a new member of the LIGHT receptor superfamily, block T cell proliferation, expression of activation markers, and production of cytokines. J Immunol. 1998;161:1786-94.

21. Tamada K, Shimozaki K, Chapoval AI, Zhu G, Sica G, et al. Modulation of T-cell-mediated immunity in tumor and graftversus-host disease models through the LIGHT co-stimulatory pathway. Nat Med. 2000;6:283-9.

22. Lu FZ, Fujino M, Kitazawa Y, Uyama T, Hara Y, Funeshima N, Jiang JY, Umezawa A, Li XK. Characterization and gene transfer in mesenchymal stem cells derived from human umbilical-cord blood. J Lab Clin Med. 2005;146:271-8.

23. Yu KY, Kwon B, Ni J, Zhai Y, Ebner R, et al. A newly identified member of tumor necrosis factor receptor superfamily (TR6) suppresses LIGHT-mediated apoptosis. J Biol Chem. 1999;274: 13733-6.

24. Morishige T, Yoshioka Y, Tanabe A, Yao X, Miuguchi H, et al. Comparison of the anti-tumor activity of native, secreted, and membrane-bound LIGHT in mouse tumor models. Int Immunopharmacol. 2010;10:26-33.

25. Hu G, Liu Y, Li H, Zhao D, Yang L, et al. Adenovirus-mediated LIGHT gene modification in murine B-cell lymphoma elicits a potent antitumor effect. Cell Mol Immunol. 2010;7:296-305.

26. Loeffler M, Le'Negrate G, Krajewska M, Reed JC. Attenuated Salmonella engineered to produce human cytokine LIGHT inhibit tumor growth. Proc Natl Acad Sci USA. 2007;104:12879-83.

27. $\mathrm{Yu} \mathrm{P}, \mathrm{Fu} \mathrm{YX}$. Targeting tumors with LIGHT to generate metastasis-clearing immunity. Cytokine Growth Factor Rev. 2008;19:285-94.

28. Fan Z, Yu P, Wang Y, Wang Y, Fu ML, et al. NK-cell activation by LIGHT triggers tumor-specific CD8+ T-cell immunity to reject established tumors. Blood. 2006;107:1342-51.

29. Rubinstein P, Rosenfeld RE, Adamson JW, Stevens CE. Stored placental blood for unrelated bone marrow reconstitution. Blood. 1993;81:679-1690.

30. Nakamura K, Ito Y, Kawano Y, Kurozumi K, Kobune Tsudal M, et al. Antitumor effect of genetically engineered mesenchymal stem cells in a rat glioma model. Gene Ther. 2004;11:1155-64.

31. Wolf D, Rumpold H, Koeck R, Gunsilius E. Mesenchymal stem cells: potential precursors for tumor stroma and targeted-delivery vehicles for anticancer agents. J Natl Cancer Inst. 2005;97:540-1.

32. Zhao BC, Wang ZJ, Ma HC, Han JG, Zhao B, et al. CXCR4/ $\mathrm{SDF}-1$ axis is involved in the lymph node metastasis of gastric carcinoma. World J Gastroenterol. 2011;19:2389-96. 